\title{
The future of electronic cigarette growth depends on youth uptake
}

\section{Simon Chapman discusses the phenomenon of "e-cigarettes" and the potential risks associated with their use}

\section{$\mathrm{T}$} he New South Wales Government recently announced that it will outlaw the sale of electronic cigarettes (ECs) to minors. For the unfamiliar, ECs are battery-powered vaporisers that produce an aerosol or vapour containing nicotine and other substances, rather than cigarette smoke, which the user inhales. Parallel laws banning sales of tobacco products to children have existed in Australian states since $1900 .{ }^{1}$ These laws have long been ignored by many retailers ${ }^{2}$ and are poorly enforced. Prosecutions are rare, with the laws being largely symbolic gestures.

The tobacco industry long ago perfected pious expressions of public concern about juvenile smoking, while knowing how essential new cohorts of young smokers are to its very survival as an industry. Private acknowledgement of its own duplicity was hardly surprising:

... this is one of the proposals that we shall

initiate to show that we as an industry are doing something about discouraging young people to smoke. This of course is a phony way of showing sincerity as we all well know.

Equally, any manufacturer or retailer of ECs wanting to maximise sales appreciates the critical importance of building demand for these products in the young, as well as the social and political unacceptability of being candid about this. Today, an ever-diminishing $12.8 \%$ of Australians aged 14 years and over smoke on a daily basis. ${ }^{4}$ The record low uptake of smoking by the young is most responsible for this. The prospect of the industry reversing this inexorably ruinous exodus has been given a major boost with the arrival of ECs.

\section{Tobacco companies' investment in e-cigarettes}

All tobacco transnationals have invested in ECs, with none desisting from their efforts to attack and dilute potent tobacco control policies nor announcing any phase-out of their combustible products. From this, we can conclude that the companies' best hopes are for people to smoke and to use ECs or "vape", not to use ECs instead of smoking. At a population level, this would be harm increasing, not reducing. ${ }^{5}$ Successful EC start-up companies are being bought up by tobacco companies, so the future of ECs is likely to be in lockstep with those companies' ambitions, driven by their concern to preserve and grow immensely more

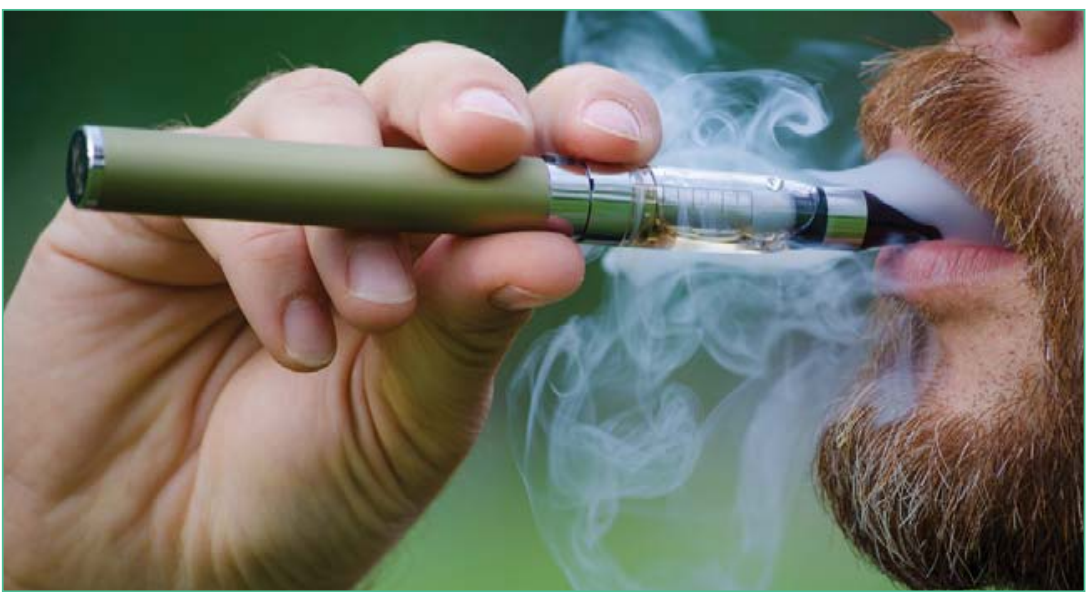

profitable cigarette sales and to maximise the hours in a day when their products can be consumed.

Australian data on daily EC use are unavailable, with a 2013 national survey finding that $15.4 \%$ of smokers aged 14 years or over had used them at least once in the past 12 months, ${ }^{6}$ despite sales of nicotine liquid or "juice" being illegal here. In the United States, where ECs are freely available and heavily marketed, rising EC use by youths has now surpassed their falling cigarette smoking prevalence. ${ }^{7} \mathrm{EC}$ advocates argue that there is thus no evidence for any gateway effect where nicotine initiation through vaping predicts uptake of smoking at higher rates than would occur without EC use. But smoking by young people has been in continual decline since 1994 in England ${ }^{8}$ and 1997 in the US ${ }^{9}$ and Australia, ${ }^{10}$ all well before the advent of ECs. Net transitioning to cigarettes or dual use with ECs in minors might be camouflaged by these broader declines. Future research will inform this important question.

Here though, a potential coalmine canary comes from a repeated Polish cross-sectional study, blithely dismissed as an outlier by vaping advocates. It found current use of ECs among Polish adolescents was dramatically higher in a 2013-14 sample than in a 2010-11 sample (29.9\% v 5.5\%) and that the prevalence of smoking tobacco cigarettes also increased $(38 \% \mathrm{~V}$ $23.9 \%)^{11}$

Simon Chapman

PhD, FASSA, HonFFPH

University of Sydney, Sydney, NSW.

simon.chapman@ sydney.edu.au

doi: 10.5694/mjal5.00304
The internet is awash with aggressive advertising for $\mathrm{ECs}^{12}$ and the wide range of models available ${ }^{13}$ make them highly attractive to young people acutely hungry for ever-changing technology with edgy semiotics. A website sponsored by cigarette manufacturer Lorillard, which also sells Blu ECs, once stated knowingly: ${ }^{14}$

Kids may be particularly vulnerable to trying e-cigarettes due to an abundance of fun flavors such as cherry, vanilla, pina-colada and berry. 
Many chemical flavourants in ECs have been approved for ingestion in foods, but not for inhalation ${ }^{15}$ up to 200 times a day, as occurs with ECs. ${ }^{16}$

\section{The evidence relating to e-cigarette use}

The volume and quality of the evidence for ECs being superior to unassisted quitting is small and often compromised by serious selection bias. EC users or "vapers" who have quit smoking understandably like to share their stories. But we have little population data on the extent to which ECs are causing prevarication about quitting, through erroneous beliefs that simply reducing smoking while dual using is harm reducing. ${ }^{17-19}$ One review concluded that real-world EC use is associated with significantly lower odds of quitting cigarettes. ${ }^{20}$

A recent systematic review of the evidence on the health risk profile of ECs concluded: ${ }^{21}$

Due to the many methodological problems, severe conflicts of interest, the relatively few and often small studies, the inconsistencies and contradictions in results, and the lack of long-term follow-up, no firm conclusions can be drawn on the safety of ECs ...
Should the many hopes be realised that ECs do indeed pose minimal health risks and significantly assist in smoking cessation, future policy development in Australia will need to carefully consider how adult smokers wanting access to these products can best be facilitated without reversing the decades-long decline in youth smoking.

EC proponents argue that nicotine is almost benign in the doses obtained through vaping. However, there is growing evidence about the role of nicotine in carcinogenesis ${ }^{22}$ and the International Agency for Research on Cancer has recently prioritised the assessment of nicotine's carcinogenicity. ${ }^{23}$

Pied Pipers in the vaping and tobacco industries have attempted to argue that concern about EC uptake in youth who would have never used any nicotine product is nothing but barely disguised moralism, akin to railing against innocuous caffeine. If they are right, those urging caution about soft touch regulation will have simply been wrong. But if the EC advocates are wrong, a less than benign genie with its pharmacological clutches around millions of young people may be extremely difficult to put back in the bottle.

Competing interests: No relevant disclosures.

Provenance: Commissioned; externally peer reviewed.

References are available online at www.mja.com.au. 
1 Tyrrell I. Deadly enemies. Tobacco and its opponents in Australia. Sydney: UNSW Press, 1999.

2 Tofler A, Chapman S. "Some convincing arguments to pass back to nervous customers": the role of the tobacco retailer in the Australian tobacco industry's smoker reassurance campaign 1950-1978. Tob Control 2003; 12 Suppl 3: iii7-iiil2.

3 Hung S. Smoking and health meeting. Philip Morris. [Memo of meeting minutes, dated 14 Feb 1973.] http://legacy.library. ucsf.edu/tid/owq24e00 (accessed Apr 2015).

4 Australian Institute of Health and Welfare. National Drugs Strategy Household Surveys (NDSHS). Highlights from the 2013 survey. Canberra: AlHW, 2014. http://www.aihw.gov.au/ alcohol-and-other-drugs/ndshs (accessed Apr 2015).

5 Chapman S. E-cigarettes: the best and the worst case scenarios for public health - an essay by Simon Chapman. BMJ 2014; 349: g5512.

6 Australian Institute of Health and Welfare. Online tables. Table 3.10. In: National Drug Strategy Household Survey. Detailed report: 2013. Canberra: AlHW, 2014. http://www. aihw.gov.au/alcohol-and-other-drugs/ndshs-2013/tables (accessed Apr 2015).

7 University of Michigan. E-cigarettes surpass tobacco cigarettes among teens [media release]. Michigan News 16 Dec 2014. http://www.monitoringthefuture.org/ pressreleases/14cigpr_complete.pdf (accessed Apr 2015).

8 Action on Smoking and Health. Young people and smoking. Fact sheet. London: ASH, Jul 2014. http://www.ash.org.uk/ files/documents/ASH_108.pdf (accessed Apr 2015).

9 US Centers for Disease Control and Prevention. Cigarette smoking among US high school students at lowest level in 22 years [media release]. 12 Jun 2014. http://www.cdc.gov/ media/releases/2014/p0612-YRBS.html (accessed Apr 2015).

10 Scollo M, Winstanley M. Prevalence of smoking - secondary students. In: Tobacco in Australia: Facts and issues. 4th ed. Melbourne: Cancer Council Victoria, 2012. http://www. tobaccoinaustralia.org.au/chapter-1-prevalence/1-6prevalence-of-smoking-secondary-students (accessed Apr 2015).

11 Goniewicz ML, Gawron M, Nadolska J, et al. Rise in electronic cigarette use among adolescents in Poland. J Adolesc Health 2014; 55: 713-715.
12 Grana RA, Ling PM. "Smoking revolution": a content analysis of electronic cigarette retail websites. Am J Prev Med 2014; 46: 395-403.

13 Zhu SH, Sun JY, Bonnevie E, et al. Four hundred and sixty brands of e-cigarettes and counting: implications for product regulation. Tob Control 2014; 23 Suppl 3: iii3-iii9.

14 Glantz S; University of California, San Francisco: Center for Tobacco Control Research and Education. Lorillard admits flavored e-cigarettes attract youth; FDA should prohibit flavors as part of the current rulemaking. 31 May 2014. http://www.tobacco.ucsf.edu/lorillard-admits-flavored-ecigarettes-attract-youth-fda-should-prohibit-flavors-partcurrent-rulema (accessed Apr 2015).

15 Flavor and Extract Manufacturers Association of the United States. The safety assessment and regulatory authority to use flavors - focus on e-cigarettes. Revised. Washington, DC: FEMA, 3 Mar 2015. http://tobacco.ucsf.edu/sites/tobacco. ucsf.edu/files/u9/FEMAGRAS Ecig 030315.pdf (accessed Apr 2015).

16 Etter JF, Bullen C. A longitudinal study of electronic cigarette users. Addict Behav 2014; 39: 491-494.

17 Tverdal A, Bjartveit K. Health consequences of reduced daily cigarette consumption. Tob Control 2006; 15: 472-480.

18 Hart C, Gruer L, Bauld L. Does smoking reduction in midlife reduce mortality risk? Results of 2 long-term prospective cohort studies of men and women in Scotland. Am J Epidemiol 2013; 178: 770-779.

19 Song YM, Sung J, Cho HJ. Reduction and cessation of cigarette smoking and risk of cancer: a cohort study of Korean men. $J$ Clin Oncol 2008; 26: 5101-5106.

20 Grana R, Benowitz N, Glantz SA. E-cigarettes: a scientific review. Circulation 2014; 129: 1972-1986.

21 Pisinger C, Dossing M. A systematic review of health effects of electronic cigarettes. Prev Med 2014; 69: 248-260.

22 Grando SA. Connections of nicotine to cancer. Nat Rev Cancer 2014; 14: 419-429.

23 Straif K, Loomis D, Guyton K, et al. Future priorities for the IARC Monographs. Lancet Oncol 2014; 15: 683-684 